Review

\title{
The Prospective Value of Dopamine Receptors on Bio-Behavior of Tumor
}

\author{
Xu Wang1,2, Zhi-Bin Wang1,2, Chao Luo ${ }^{1,2,4}$, Xiao-Yuan Mao',2, Xi Li1,2, Ji-Ye Yin ${ }^{1,2}$, Wei Zhang ${ }^{1,2,3}$, \\ Hong-Hao Zhou ${ }^{1,2,3}$, Zhao-Qian Liu ${ }^{1,2,3}$ \\ 1. Department of Clinical Pharmacology, Xiangya Hospital, Central South University, Changsha 410008, P. R. China; \\ 2. Institute of Clinical Pharmacology, Central South University, Hunan Key Laboratory of Pharmacogenetics, Changsha 410078, P. R. China; \\ 3. National Clinical Research Center for Geriatric Disorders, Xiangya Hospital, Central South University, Changsha 410008, P. R. China; \\ 4. School of Life Sciences, Central South University, Changsha, Hunan 410078.
}

$\triangle$ Corresponding author: Professor Zhao-Qian Liu: Department of Clinical Pharmacology, Xiangya Hospital, Central South University, Changsha 410008, P. R. China; Institute of Clinical Pharmacology, Central South University; Hunan Key Laboratory of Pharmacogenetics, Changsha 410078, P. R. China. Tel: +86 731 89753845, Fax: +86 731 82354476, E-mail: liuzhaoqian63@126.com.

(c) Ivyspring International Publisher. This is an open access article distributed under the terms of the Creative Commons Attribution (CC BY-NC) license (https://creativecommons.org/licenses/by-nc/4.0/). See http://ivyspring.com/terms for full terms and conditions.

Received: 2018.06.10; Accepted: 2019.02.07; Published: 2019.03.03

\begin{abstract}
Dopamine receptors are belong to the family of $\mathrm{G}$ protein-coupled receptor. There are five types of dopamine receptor (DR), including DRD1, DRD2, DRD3, DRD4, and DRD5, which are divided into two major groups: the D1-like receptors (DRD1 and DRD5), and the D2-like receptors (DRD2, DRD3, and DRD4). Dopamine receptors are involved in all of the physiological functions of dopamine, including the autonomic movement, emotion, hormonal regulation, dopamine-induced immune effects, and tumor behavior, and so on. Increasing evidence shows that dopamine receptors are associated with the regulation of tumor behavior, such as tumor cell death, proliferation, invasion, and migration. Recently, some studies showed that dopamine receptors could regulate several ways of death of the tumor cell, including apoptosis, autophagy-induced death, and ferroptosis, which cannot only directly affect tumor behavior, but also limit tumor progress via activating tumor immunity. In this review, we focus mainly on the function of the dopamine receptor on Bio-behavior of tumor as a potential therapeutic target.
\end{abstract}

Key words: dopamine receptor, autophagy, tumor immunity, ferroptosis

\section{Introduction}

Dopamine is a major catecholamine neurotransmitter, could be synthesized in the central nervous system and mesenteric, such as the digestive tract, spleen and pancreas [1-3]. In the mammalian brain, there are four dopaminergic pathways have been found, including nigrostriatal, mesolimbic, mesocortical, and tuberoinfundibular. These neurons have an important role in central nervous system, such as locomotor activity, appetite, emotion, reward, sleep, attention, cognition, working memory, and learning. In the periphery dopamine could be a regulator of heart rate, endocrine, cardiovascular function, kidney function, gastrointestinal motility, immune system, and so on $[4,5]$. DRs extensively expressed on brain, retina, gastrointestinal tract, kidney, adrenal glands, heart, sympathetic ganglia, and blood vessels [2]. DRs are a family of metabotropic $G$ protein-coupled receptor, which is 7-transmembrane [6]. At present, there are five types of DRs, including DRD1, DRD2, DRD3, DRD4, and DRD5. According to their different regulation of adenylyl cyclase (AC) activity, DRs could be divided into two families: D1-like DRs and D2-like DRs. The production of cAMP can be stimulated by acting D1-like DRs, opposite to D2-like DRs (DRD2, DRD3, and DRD4). Compared with D1-like DRs, D2-like DRs have a larger third cytoplasmic loop and a shorter carboxyl-terminal tail [7]. The genetic structure of two type dopamine receptor could be also different. In coding regions, D1-like DRs do not possess introns, while D2-like DRs 
contains several introns. The gene of DRD2, DRD3, and DRD4 respectively contain six, five, and three introns [8]. For this, D2-like DRs can generate splice variants. D2S and D2L are two isoforms of DRD2, generated by alternative splicing of an 87-base-pair exon between introns 4 and 5 [1]. DRD3 can generate splice variants too, but encoding nonfunctional proteins [9]. The gene of DRD4 can generate polymorphic variations, a 48-base-pair sequence in the third cytoplasmic was described as a repeat sequence $[10,11]$. In the brain, both DRD1 and DRD2 play a major role in learning and working memory. While the role of DRD3, DRD4, and DRD5 in the brain still unknown. In periphery, DRD1, DRD2, and DRD4 could be a regulator of renal function, blood pressure, and gut motility [1].

Dysfunction of the dopaminergic system is related to schizophrenia and Parkinson's disease (PD), and targeting the dopamine receptor is a major way of treatment [12]. Some epidemiological studies declared that schizophrenia has a lower cancer incidence, while the evidence of schizophrenia has a higher risk of cancer also be reported [13-16]. Even in the same kind of cancer, the result would be very different [17]. An interesting epidemiologic study demonstrated that schizophrenic patients who have elevated DRD2 signaling, the risk of cancers would be increased, and DRD2 antagonists make this risk return to normal
[18-20]. There are similar epidemiologic studies demonstrated that the risk of cancer, especially in smoking-related cancer, is declined in patients with PD. While patients with PD would have an increased risk of malignant melanoma, non melanoma skin cancer and breast cancer also be reported [21-23]. These findings imply that the dopaminergic system may be connected to the development of cancer.

Polymorphisms of DRs have been shown to be related to risking of colorectal, non-small cell lung cancer and gastric cancer [24-26]. High levels of DRD2 expression in gastric cancer, neuroendocrine tumors , glioblastoma, breast cancer, and others ( Table 1) have been founded [26-29]. The elevated expression of DRD2 in patients with neuroendocrine tumors would have longer time to progression [27]. Interestingly, the high level of DRD2 in patients with gastric cancer would have higher survival duration [26]. So DRD2 might play a different role in different type of cancer. DRD4 involved the malignant phenotype of pediatric medulloblastomas [30]. The expression of DRD4 is connected to survival of patients with GBM. High level of DRD4 expression has worse survival than low of DRD4 expression [31]. Accumulated evidence shows that DRs can play a vital role in cancer. In this review, we summarized the potential roles of DRs in cancer.

Table 1. The polymorphisms and level of dopamine receptors in cancers.

\begin{tabular}{|c|c|c|}
\hline Type of cancers & Relationship between dopamine receptors and cancer & References \\
\hline breast cancer & DRD1 $\uparrow, \mathrm{DRD} 2 \uparrow, \mathrm{DRD} 3 \uparrow, \mathrm{DRD} 4 \uparrow$ & [29] \\
\hline cervical cancer & DRD2 $\uparrow$ & [39] \\
\hline \multirow[t]{4}{*}{ cholangiocarcinoma } & Mz-chA-1: DRD1 $\uparrow$, DRD2 $\uparrow, \mathrm{DRD} 3 \uparrow, \mathrm{DRD} 4 \downarrow$,DRD5 $\uparrow$ & [64] \\
\hline & HuCCT-1: DRD1 $\downarrow$, DRD2 $\uparrow$, DRD4 $\downarrow, D R D 5 \downarrow$ & [64] \\
\hline & SG231: DRD2 $\downarrow$, DRD3 $\downarrow$, DRD $4 \downarrow$,DRD $5 \downarrow$ & [64] \\
\hline & CCLP-1: DRD $1 \downarrow$, DRD2 $\uparrow$, DRD3 $\downarrow$, DRD4 $\downarrow$, DRD5 $\downarrow$ & [64] \\
\hline \multirow[t]{4}{*}{ colorectal cancer } & DRD2 $\downarrow$;DRD2 polymorphisms $-141 \mathrm{Cdel}$, $957 \mathrm{~T}>\mathrm{C}, 1412 \mathrm{~A}>\mathrm{G}$ are associate with colorectal cancer. & [123] \\
\hline & HCT116: DRD1 $\uparrow$, DRD $2 \uparrow, D R D 5 \uparrow$ & [84] \\
\hline & HT29: DRD1 $\uparrow$, DRD2 $\uparrow, D R D 5 \uparrow$ & [84] \\
\hline & The DRD2 rs1799732 CT, rs1800497 TT are associated increase cancer risk. & [24] \\
\hline corticotroph adenomas & DRD2 $\uparrow$ & [124] \\
\hline gastric cancer & $\mathrm{DRD} 2 \uparrow$ & [26] \\
\hline \multirow[t]{2}{*}{ glioblastoma } & DRD2 $\uparrow$ & [28] \\
\hline & $\mathrm{U} 251: \mathrm{DRD} 1 \uparrow, \mathrm{DRD} 2 \uparrow, \mathrm{DRD} 5 \uparrow$ & [84] \\
\hline \multirow[t]{2}{*}{ hepatic carcinoma } & DRD1 $\downarrow$, DRD5 $\uparrow$ & [94] \\
\hline & Hep3B: DRD1 $\uparrow$, DRD5 $\uparrow$ & [84] \\
\hline lung cancer & DRD2 $\uparrow$ & [125] \\
\hline neuroblastoma & SKNAH: DRD $1 \uparrow$, DRD $2 \uparrow$, DRD $4 \uparrow, D R D 5 \uparrow$ & [84] \\
\hline \multirow[t]{3}{*}{ neuroendocrine } & DRD $2 \uparrow$ & [126] \\
\hline & $\mathrm{DRD} 2 \uparrow$ & [27] \\
\hline & DRD2 $\uparrow$ & [127] \\
\hline non-small cell lung cancer & DRD2 polymorphisms -141Cdel, 3208G $>$ T; DRD4 -521C $>$ T are associated with increase NSCLC risk. & [25] \\
\hline ovarian & DRD $2 \uparrow$ & [53] \\
\hline pancreatic cancer & DRD $2 \uparrow$ & {$[40]$} \\
\hline \multirow[t]{2}{*}{ pheochromocytoma } & DRD $2 \uparrow$ & [128] \\
\hline & DRD $2 \uparrow$ & [129] \\
\hline pituitary adenoma & DRD2 $\uparrow$ & {$[130]$} \\
\hline small cell lung cancer & DRD2 $\uparrow$, DRD $4 \uparrow, D R D 5 \uparrow$ & [70] \\
\hline
\end{tabular}




\section{Dopamine Receptor and Cell Death}

\section{Dopamine receptor and apoptosis}

It has been documented that dopamine can decrease cell viability and induce apoptosis in K562 leukaemia cells, human oral tumour cells, rat pituitary tumour cells and human SK-N-MC neuroblastoma cells in vitro [32-35]. Meanwhile, dopamine can reduce the frequency of cancer stem cell and induce apoptosis of cancer stem cell in vitro have been demonstrated in breast cancer. The combination of dopamine and sunitinib can enhance the response of sunitinib in drug-resistant breast cancer. And DRD1 might play a significant role on this as $\mathrm{SCH} 23390$, the antagonist of DRD1, completely reversed the effect [36]. The effect of dopamine in human SK-N-MC neuroblastoma cells can also be partly reversed by SCH23390. So DRD1 involve in the dopamine's cytotoxic on SK-N-MC [35]. Furthermore, induction of apoptosis via targeting DRs has been reported in various cancers. The role of different types of DRs in apoptosis can be different. SKF38393 is an agonist of DRD1, Jun Gao and Feng Gao demonstrated that treated with SKF38393 reduced the viability of osteosarcoma cells (OS732) and cell apoptosis would be raised in vitro. The over expression of DRD1 in OS732 cells, the cell apoptosis can also be increased [37]. Thioridazine is known as a blocker of DRD2. Previous studies have implied that thioridazine have an effective role in anti-cancer [38]. Treating with thioridazine for $24 \mathrm{~h}$ in SiHa cells in vitro, the viability of cells was considerably decreased when the concentration was over $20 \mu \mathrm{M}$, coupled with a down regulation of DRD2 expression. AnnexinVassay showed that more apoptosis was increased, and comet assay have a higher percentage of comet formed when $\mathrm{SiHa}$ cells exposed to thioridazine. That means cell apoptosis can be induced by thioridazine via targeting DRD2 [39]. Dopamine-induced cell death was seen in rat pituitary tumor cell lines in vitro. DNA laddering and caspase- 3 was triggered by dopamine can be prevented by haloperidol, which means DRD2 involve the process of Dopamineinduced cell death [34]. Pimozide, a DRD2 inhibitor, can induce cell-cycle arrest in the G1 phase in pancreatic cancer cells in vitro. The activity of caspase $3 / 7$ can be activated by pimozide, and the number of apoptotic cells was increased [40]. Neurofibromatosis type 1 is just an autosomal-domainant neurogenetic disorder. The gene of neurofibromatosis type 1 can encode a tumor suppressor protein called neurofibro$\min$. The neurofibromin might increase the apoptosis in malignant peripheral nerve sheath tumor cells (MPNST cells) in the condition of serum deprivation [41]. DRD3 involved the function of neurofibromin has been declared [42]. 7-OH-PIPAT, a selective DRD3 agonist, would protect MPNST cells from apoptosis in the condition of serum deprivation in vitro. The expression of neurofibromin can be changed by 7-OH-PIPAT. So DRD3 might have an anti-apoptosis role in cancer cells, but the detail mechanisms still unknown [43]. DRD4 can down regulate the expression of cell-cycle genes in vitro. Treating with DRD4 antagonists in G411 and G362 cells, a $\mathrm{G}_{0} / \mathrm{G}_{1}$ phase arrest and the activity of caspase $3 / 7$ can be induced. This result suggests that the inhibition of DRD4 can increase cell apoptosis in vitro [31]. In GH3 cells, treatment with the DRD5 agonist SKF83959 can induce apoptosis in a dose-dependent manner [44].

\section{Dopamine receptor and autophagy}

Autophagy is a highly conserved progress, function as a scavenger in cells. Autophagy can format a double membrane vesicle named autophagosomes. Some substrates can be engulfing by autophagosomes such as endoplasmic reticulum, ribosomes, mitochondria, nuclear fragments, protein aggregates, bacteria, and viruses $[45,46]$. These substrates can be delivered to the lysosome, and degraded by lysosomal enzymes. The basal level of autophagy protects cells from stressful conditions. While redundant autophagy have a function of promoting non-apoptotic cell death [47]. Autophagy is connected to tumorigenesis and acquired chemotherapeutic resistance has been widely demonstrated [48-50]. Targeting autophagy is a promising way of treating tumors.

It has been demonstrated that dopamine can induce autophagic cell death in SH-SY5Y cells [51]. The production of ROS might be responsible for the autophagic cell death cause by dopamine. Sertindole, an antagonist of DRD2s, can induce autophagy in SH-SY5Y cells in vitro. And ATG5s play a vital role in the autophagy caused by Sertindol [47]. Inducing autophagy in PC12, MES23.5, and differentiated SH-SY5Y cells by treating pramipexole and quinpirole, the DRD2 and DRD3 agonists, have been demonstrated in vitro. This process might be related to an MTOR-independent but BECN1 dependent pathway. Pramipexole and quinpirole can increase the transcription and expression of BECN1 and promote its combined with PtdIns3K [52]. Autophagy induced by thioridazine might be responsible for thioridazine-induced cytotoxicity in ovarian cancer cells [53]. Ammonia, a product of metabolite of proteins and nucleic acids, can induce autophagy in vitro [54]. The increase level of LC3B caused by ammonia would be reduced when DRD3 knockdown in HeLa cells. Ammonia changes the location of MTOR, and DRD3 was involved in this process [55]. DRD4 antagonists can increase the level of LC3-II in 
glioblastomas neural stem cells in vitro, caused by impaired autophagy flux. Accumulation of p62 and ubiquitinated protein conjugates accompanied by the increase of LC3-II has been observed, which show that DRD4 antagonism exert the function of cytotoxicity by blocking autophagy [31]. In pituitary tumor cells, active DRD5 can suppress the function of MTOR by increasing the level of ROS. SKF83959, a DRD5 agonist, can increase the level of LC3-II and block the degradation of SQSTM1. That means active DRD5 can block the autophagic flux [44]. So DRs are a set of prospective regulator of autophagy.

\section{Dopamine receptor and ferroptosis}

Ferroptosis, a newly found form of cell death, is characterized by iron and lipid ROS accumulation [56]. Ferroptosis is distinguishable from apoptosis, necroptosis and autophagy in morphological, biochemical, and genetic features [57]. Erastin has been widely used to induce ferroptosis, can enhance sensitivity of the cancer cell to chemotherapeutic [58]. While dopamine can inhibit ferroptosis induced by erastin in PANC1 cells have been documented. The cell viability of cancer cell would be increased when treated with dopamine $(12.5-50 \mu \mathrm{M})$. Detail study found that the degradation of DRD4 protein is promoted by erastin, while the gene expression of DRD5 is induced. Ferrostatin-1, a ferroptosis inhibitor, can block the change of DRD4 and DRD5 caused by erastin. Dopamine can inhibit the degradation of DRD4 protein induced by erastin, but have no influence on DRD5 expression [59]. Therefore, dopamine receptor of DRD4 and DRD5 might regulate chemosensitivity of cancer via inhibiting ferroptosis.

\section{Dopamine Receptor and Cancer Cell Proliferation}

Several in vivo studies declared that dopamine can suppress cancer growth. For example, rat adenocarcinoma cells were implanted in two kinds of rat, APO-SUS with high dopaminergic reactivity and APO-UNSUS with low dopaminergic reactivity. In APO-SUS animals, the size of tumors was smaller compared with APO-UNSUS animals [60]. In the model of stress induced ovarian, the level of dopamine is decreased after 3 to 14 of stress. In stressed mice, treatment with $75 \mathrm{mg} / \mathrm{kg}$ of dopamine has a significantly function of inhibiting cancer growth in vivo [61]. In the tissues of gastric cancer in both humans and MNNG-induced rats, the level of dopamine was lower than normal stomach tissues. A low nontoxic dose of dopamine could be seen as an inhibitor of the growth of gastric cancer and angiogenesis in MNNG-induced model [62]. Dopamine can enhance the efficacy of anticancer drugs in mice models of breast and colon cancer has also been reported [63]. While an in vitro study demonstrated that the increased dopamine secretion could stimulate the proliferation of cholangiocarcinoma cells, and pretreatment of L-741,626 25 (DRD2 inhibitor) and L-745,870 trihydrochloride 27 (DRD4 inhibitor) could reverse this effect of dopamine [64].

Previous studies proved that dopamine inhibits tumor growth by suppressing angiogenesis, and DRD2 plays a vital role in this process [65]. Other pathways also involve the process of dopamine inhibit tumor growth, such as induce oxidative stress, inhibit the activity of the enzyme ribonucleotide reductase, increase the activity of intracellular lysosomal enzyme activity, and activation of immune system, however which DRs responsible for these pathways still need further to study [34]. In DRD2 knockout mice, more angiogenesis and tumor growth were noted [66]. DRD2 agonists could abolish lung tumor progression in murine models by inhibition of tumor angiogenesis and reduction of tumor infiltrating myeloid derived suppressor cells in vivo [67]. Endocytosis of VEGFR-2 can be induced by dopamine via DRD2, which is important for promoting angiogenesis, thereby preventing vascular permeability factor/vascular endothelial growth factor-A binding, receptor phosphorylation, and subsequent signaling steps [68].

Dopamine can inhibit gastric cancer cell proliferation by activating DRD2 via down-regulation of IGF-IR and AKT phosphorylation. Pretreatment with quinpirole $(50 \mu \mathrm{M})$, a DRD2 agonist, can inhibit IGF1-induced gastric cancer cell proliferation in vitro [69]. Treatment with quinpirole $(10 \mu \mathrm{M})$ can inhibit the proliferation of primary small cell lung cancer in a dose and time dependent in vitro [70]. Furthermore, the proliferation of CD133+ve cancer stem cells in non-small cell lung cancer can also be inhibited by treating quinpirole $(1 \mu \mathrm{M}$ or $10 \mu \mathrm{M})$ in vitro and vivo [71]. Fisetin, function as DRD2 agonist, showed significantly inhibitory role in HCC-LM3 proliferation in vitro when the concentration over $10 \mu \mathrm{M}$ [72]. Bromocriptine, a DRD2 agonist, could suppress MCF-7 cells growth at a concentration of 6.25 to 100 $\mu \mathrm{M}$ in vitro [73]. In aldosterone-producing adenoma, bromocriptine can inhibit angiotensinII-induced cell proliferation by attenuating angiotensinII-induced phosphorylation of PK-stimulated cyclic D1 protein expression and cell proliferation in vitro [74]. The proliferation of Hepa1-6, SMMC-7721 and HCC-LM3 cells can be inhibited by bromocriptine in a concentration-dependent manner [75]. Though bromocriptine has been utilized clinically for reducing tumor mass of prolactinomas, the resistance still existence in $5-18 \%$ of patients [76]. Knockdown of 
DRD2 expression in the pancreatic cancer cell lines can inhibit the proliferation of cells. Treatment with different concentration of pimozide, an FDA-approved DRD2 inhibitor for the therapy of schizophrenia, can get a dose-dependent inhibitory effect on pancreatic cancer cell lines growth in vitro. The higher level of DRD2 in cell lines, the stronger pimozide effect it will be [40]. Treating with thioridazine $(32 \mathrm{mg} / \mathrm{kg})$ in a murine breast cancer model, the tumor volume was significantly reduced. And immunohistochemistry showed that the marker of the cell cycle Ki67 was decreased. That means cell proliferation was inhibited by thioridazine in vivo [77]. Treating with thioridazine $(10 \mu \mathrm{M})$ and compared to other known DR antagonists, clozapine $(100 \mu \mathrm{M})$ and chlorpromazine $(10 \mu \mathrm{M})$ in AML cell lines. These three of DR antagonists reduced the number of AML cells upon treatment [78]. DRD2 was overexpressed in ovarian cancer cells, and treatment with thioridazine $(15 \mu \mathrm{M})$ inhibited the proliferation of ovarian cancer cells in vivo and in vitro [53]. The inhibition of $\mathrm{FAK} / \mathrm{mTOR}$ signaling was associated to the inhibition of ovarian cancer cells growth in vitro by thioridazine [79], the reducing phosphorylation of VEGFR2 and the inhibition of $\mathrm{PI} 3 \mathrm{~K} / \mathrm{mTOR}$ signaling were responsible for the inhibition of ovarian carcinoma growth in vivo by thioridazine [80]. Trifluoperazine, a clinically-used antidepressant drug by targeting DRD2, can inhibit the growth and proliferation of glioblastoma in a dose-dependent manner in vitro [81]. Furthermore, in vivo and in vitro study declared that trifluoperazine can inhibit the growth of cancer stem cell and overcome the drug resistance of lung cancer $[82,83]$. ONC201's anti-cancer effect has been reported to relate to DRD2, though DRD2 is not responsible for all of this effect. And DRD2-antagonist, L-741,626 and PG01037 could significantly decrease the cell viability in colorectal cancer cells. By the way, the combination with SCH39166, a selective D1/D5 antagonist, increases ONC201's anti-cancer activity in colorectal cancer cell lines in vitro [84]. In breast cancer cell, in vivo and in vitro research shown that sulpiride, can increase the anti-cancer effect of dexamethasone, and DRD2 might responsible for this effect as treating DRD2 agonist 7-OH-DPAI can reverse the enhanced anti-cancer effects in vivo and decrease the cancer stem cell population in tumor tissues [85].

Other DRs also involved the process of cancer cell proliferation. Previous in vivo study showed that angiogenic induced by mouse ovarian tumor cannot be prevented by DRD1 agonist SKF38393 $(10 \mathrm{mg} / \mathrm{kg})$ or DRD1 antagonist SCH23390 (10 mg/ kg) [68]. Conflict research demonstrated that DRD1 contributes to dopamine induced tumor angiogenesis. Lewis lung carcinomas were implanted into DRD1 knockout mice and wild-type mice. The growth of the tumor was slower in DRD1 knockout compare with wildtype mice. And tumor vessels from DRD1 knockout mice were decreased [86]. DRD1 are expressed in osteosarcoma cells, treating DRD1 agonist SKF38393 $(10 \mu \mathrm{M})$ can inhibit the proliferation of osteosarcoma in vitro. The effect of SKF38393 on the proliferation of osteosarcoma is related to down-regulation of the ERK1/2 and PI3K-Akt pathways by activating DRD1 [87]. A screening of $\sim 1,000$ biological active compounds implied that a selective agonist of DRD1, A77636 $(2 \mu \mathrm{M})$, could inhibit the proliferation of breast cancer cells in vitro. In the animal model of bearing breast cancer cells, the growth of the tumor can be obviously inhibited by injecting of A77636 (2 $\mathrm{mg} / \mathrm{kg}$ ) for 2 weeks [88]. The DR1 agonist SKF82958 can increase the concentration of intratumoral cisplatin in nude mice bearing SKOV3ip1 tumors, and the growth of the tumor was significantly inhibited compared with the group treated with cisplatin alone in vivo [89]. Knockdown of DRD4 in GNS cell lines can significantly reduce cell proliferation. L-741,742 function as DRD4 antagonists can selectively inhibit GNS growth and promote differentiation of normal neural stem cells in vitro [31]. LQFM018, a novel synthetized piperazin-containing compound, can inhibit the growth and induce death of K562 leukemic cells in vitro by binding DRD4 [90]. The viability of GH3 cells can be decreased by SKF83959, a DRD5 agonist. Knock-down the expression of DRD5 can abolish this function. Primary pituitary cells that expressed DRD5 protein was all sensitive to SKF83959, while cells expressed DRD5 extremely low have no effect on SKF83959. And the size of the tumor in nude mice bearing human gastric cancer cells was smaller than control by treating SKF83959 $(1 \mathrm{mg} / \mathrm{kg})$ in vivo [44].

In summary, targeting DRD1 or DRD2 can suppress cancer cell proliferation have been widely reported, while few studies found other DRs can also have the same effect. But the detail mechanism still needs further research.

\section{Dopamine Receptor and Cancer Cell Invasion and Migration}

EGF is a critical factor that is related to tumor invasion and migration. Pretreatment of gastric cell lines with dopamine inhibited EFG $(100 \mathrm{ng} / \mathrm{ml})$ -induced invasion and migration, and the maximum inhibitory effect was appeared at $800 \mathrm{nM}$ in vivo. MMPs play a pivotal role in the invasion and metastasis of cancer. Dopamine can down-regulate the level of MMP-13 via DRD2. Knockdown of DRD2 abolished the function of dopamine on EGF-induced invasion and migration [91]. A study showed 
DRD2-specific agonist BIM53097 can inhibit the proliferation of non-function pituitary in vitro [92]. And another study documented that BIM53097 (1 $\mu \mathrm{M})$ inhibits human tumorous pituitary cells migration and invasion via activating cofilin pathway in vitro. Treatment with a selective inhibitor of ROCK can abrogate cofilin pathway induced by DRD2 activation [93]. The Matrigel invasion assay indicated that quinpirole $(1 \mu \mathrm{M}$ or $10 \mu \mathrm{M})$ can decrease the invasion of CD133+ve tumor cells derived from A549 NSCLC cell line in vitro [71]. A77636 have an inhibitory effects on breast cancer cell motility in a dose-dependent manner at the concentrate of 2.5 , and $10 \mu \mathrm{M}$ in vitro. In the animal model of bone metastasis, A77636 reduced osteolytic lesions and prevented mechanical weakening of the femur and tibia [88]. Compared with control cells, the motility of Hepatocellular carcinoma (HCC) cells would be reduced when pretreated with thioridazine $(10 \mu \mathrm{M})$ for 72 hours. The motility-related genes' expression can be decreased by exposing thioridazine [94]. As an antipsychotic drug, the effect of trifluoperazine comes from its ability to abolish DRD2 activity. Downregulate the expression of DRD2 in prostate cancer and fibrosarcoma cell lines by trifluoperazine causes a decrease cell migration compared with control. Haloperidol, another antipsychotic known as DRD2 inhibitor, can reduce migration of prostate cancer cell lines, similar to those treated with trifluoperazine in vitro [95]. Breast cancer cell lines treated with fenoldopam $(1 \mathrm{nM})$, a peripheral DRD1 agonist that does not penetrate the brain, significantly suppress FBS-induced invasion [96].

\section{Dopamine Receptor and Tumor Immunity}

Recently, immunotherapy has been seen as a promising strategy against tumors. An emerging number of studies indicated that dopamine can be a regulator of the immune system. It has been documented that DRD1 involve the inhibit proliferation and cytotoxicity of CD4+ and CD8+ $\mathrm{T}$ cells in a vitro experiment [97]. DRs have been found in several immune cells, such as effector $\mathrm{T}$ cells, regulatory $\mathrm{T}$ cells, B cells, NK cells, Monocytes, Macrophages, Dendritic cells (DCs), Neutrophils, and eosinophils, which implies DRs might involve the regulation of immune cell's activities [98].

Regulatory $\mathrm{T}$ cells (Tregs) and effector $\mathrm{T}$ cells (Teffs) have the capacity to produce dopamine, and once dopamine is released from Tregs, the function of Tregs would be inhibited via D1-like receptors (probably the DRD5). Suppression of Tregs induced by dopamine can make Teffs be activated and proliferated. Therefore, dopamine can be viewed as a suppressor of the suppressors [99]. While cytokine secretion can be induced by dopamine or selective agonists of DRD2 or DRD3 in normal human T cells via activating the DRD2 and DRD3 (primarily). And the concentration of dopamine is the main factor that influences the function of dopamine on $\mathrm{T}$ cells. Dopamine at the physiological concentration is good for Teffs exert its function, while at extremely high concentration (0.1-1 $\mathrm{mM}$ ) would have a toxic effect on both resting and activated Teffs [100].

DCs, a specialized antigen-presenting cells, can capture and processing of tumor-derived antigens, which play a crucial role in anti-immune response [101]. Tumor-derived antigens are cross-presented to CD8+T cells by dendritic cells, inducing differentiation of $\mathrm{CD} 8+\mathrm{T}$ cells into cytotoxic $\mathrm{T}$ lymphocytes (CTLs). Tumor cells are identified as foreign antigens by effector $\mathrm{CD} 8+\mathrm{T}$ cells, and effector $\mathrm{CD} 4+\mathrm{T}$ cells function as an activator of CD8+T cells. Tumor cells would be murdered by effector CD8+T cells via secreting cytotoxic granules [102]. Previous studies have shown that the migration and homing of naive CD8+T cells can be induced by dopamine through DRD3 [103]. CD4+T lymphocyte has three subsets: naive, central memory $\left(\mathrm{T}_{\mathrm{CM}}\right)$, and effector memory $\left(\mathrm{T}_{\mathrm{EM}}\right)$. All the five DR have been found on the CD4+T cells, while the expression patterns of DRs are different in three subsets. The expression level of D1-like DRs is higher than D2-like DRs in naive T cells, which opposite to other two subsets [104]. Notably, down-regulate the function of DRD3 in DCs can promote cytotoxic $\mathrm{T}$ response in tumor-bearing mice by enhancing antigen cross presentation and $\mathrm{CD} 8+\mathrm{T}$ cell activation, while it has no effect on CD4+T cell response [105]. But dopamine released by the DCs can influence $\mathrm{CD} 4+\mathrm{T}$ helper differentiation, polarization, cytokine secretion and effector function have been demonstrated [106].

Increasing researches demonstrate that myeloidderived suppressor cells (MDSCs), a heterogeneous group of immune cells including immature macrophages, DCs, and granulocytes with immunosuppressive function. Suppressing the function of MDSCs is expected to increase host immune responses and improve cancer immunotherapy [107]. DA-treated tumor-bearing mice $(50 \mathrm{mg} / \mathrm{kg} /$ day $)$ showed a smaller tumor size and a decrease accumulation of MDSCs in the spleen compared with control [108]. Stimulation of NO production is responsible for MDSCs inhibit immune responses. Further research declares that dopamine can inhibit NO production through down-regulation of ERK and JNK signaling via D1-like receptor. There are inconsistent studies about the function of D2-like receptor on MDSCs [109]. In the animal model of lung cancer, a study 
founded that D2-like receptor agonist quinpirole $(10 \mu \mathrm{M})$ has no effect on inhibitory of MDSCs, which are isolated from splenocytes and bone marrow cells of mice, while another study shown that DRD2 agonist cabergoline $(5 \mathrm{mg} / \mathrm{kg})$ can inhibit MDSCs [67].

Table 2. Dopamine receptors agonist or antagonist function as an inhibitor of cancer.

\begin{tabular}{|c|c|c|c|c|}
\hline Substance & Targets & $\begin{array}{l}\text { Activation or } \\
\text { inhibition of } \\
\text { dopamine } \\
\text { receptor }\end{array}$ & Type of cancers & $\begin{array}{l}\text { Refere } \\
\text { nces }\end{array}$ \\
\hline A77636 & DRD1 & active & breast cancer & {$[88]$} \\
\hline Fenoldopam & DRD1 & active & breast cancer & [96] \\
\hline SKF82958 & DRD1 & active & ovarian & [89] \\
\hline SKF38393 & DRD1 & active & osteosarcoma & {$[37,87]$} \\
\hline SCH39166 & $\begin{array}{l}\text { DRD1, } \\
\text { DRD5 }\end{array}$ & inhibit & colorectal cancer & [84] \\
\hline BIM53097 & DRD2 & active & pituitary & {$[92,93]$} \\
\hline \multirow[t]{4}{*}{ Bromocriptine } & DRD2 & active & breast cancer & [73] \\
\hline & & & $\begin{array}{l}\text { aldosterone-producing } \\
\text { adenoma }\end{array}$ & {$[74]$} \\
\hline & & & hepatic carcinoma & [75] \\
\hline & & & prolactinomas & [76] \\
\hline Fisetin & DRD2 & active & hepatic carcinoma & {$[72]$} \\
\hline \multirow[t]{2}{*}{ Haloperidol } & DRD2 & inhibit & pituitary & {$[34]$} \\
\hline & & & prostate cancer & [95] \\
\hline L-741,626 & DRD2 & inhibit & colorectal cancer & [84] \\
\hline \multirow[t]{3}{*}{ Olanzapine } & DRD2 & inhibit & glioblastoma & $\begin{array}{l}{[117,} \\
118]\end{array}$ \\
\hline & & & lung cancer & [119] \\
\hline & & & pancreatic cancer & [119] \\
\hline PG01037 & DRD2 & inhibit & colorectal cancer & [84] \\
\hline \multirow[t]{3}{*}{ Pimozide } & DRD2 & inhibit & pancreatic cancer & [40] \\
\hline & & & prostate cancer & [120] \\
\hline & & & glioblastoma & [121] \\
\hline \multirow[t]{3}{*}{ Quinpirole } & DRD2 & active & gastric cancer & [69] \\
\hline & & & small lung cancer & {$[70]$} \\
\hline & & & non small lung cancer & [71] \\
\hline Sertindole & DRD2 & inhibit & neuroblastoma & [47] \\
\hline Sulpiride & DRD2 & inhibit & breast cancer & [85] \\
\hline \multirow[t]{5}{*}{ Thioridazine } & DRD2 & inhibit & AML & {$[78]$} \\
\hline & & & breast cancer & [77] \\
\hline & & & cervical cancer & {$[38,39]$} \\
\hline & & & hepatic carcinoma & [94] \\
\hline & & & ovarian cancer & $\begin{array}{l}{[53,79,} \\
80]\end{array}$ \\
\hline \multirow[t]{3}{*}{ Trifluoperazine } & DRD2 & inhibit & prostate cancer & [95] \\
\hline & & & glioblastoma & [81] \\
\hline & & & lung cancer & {$[82]$} \\
\hline \multirow[t]{2}{*}{ Pramipexole } & $\begin{array}{l}\text { DRD2, } \\
\text { DRD3 }\end{array}$ & active & $\begin{array}{l}\text { adrenal } \\
\text { pheochromocytoma }\end{array}$ & {$[52]$} \\
\hline & & & neuroblastoma & {$[52]$} \\
\hline \multirow[t]{2}{*}{ Quinpirole } & $\begin{array}{l}\text { DRD2, } \\
\text { DRD3 }\end{array}$ & active & $\begin{array}{l}\text { adrenal } \\
\text { pheochromocytoma }\end{array}$ & {$[52]$} \\
\hline & & & neuroblastoma & {$[52]$} \\
\hline 7-oh-PIPAT & DRD3 & active & MPNST & {$[43]$} \\
\hline L-741,742 & DRD4 & inhibit & GNS & [31] \\
\hline \multirow[t]{2}{*}{ SKF83959 } & DRD5 & active & pituitary tumor & {$[44]$} \\
\hline & & & gastric cancer & {$[44]$} \\
\hline Clozapine & DRs & inhibit & AML & {$[78]$} \\
\hline Chlorpromazine & DRs & inhibit & AML & {$[78]$} \\
\hline
\end{tabular}

NK cells are able to obliterate tumor cells and they play an important role in limiting tumor metastasis [110]. NK cells expression DRD2, DRD3,
DRD4, DRD5, and lack of DRD1. IFN-y, a cytokine that plays an important role in immune responses against tumors, can be produced by NK cells. And NK cells can control the tumor-promoting function of neutrophils depends on IFN- $\gamma$ [111]. A low dose of dopamine can suppress the production of IFN- $\gamma$ via DRD5 signaling on activated NK cells [99].

Tumor associated macrophages (TAMs) are usually educated by tumor cells to become their partners, avoiding tumor recognized by immune system [112]. TAMs are presented as either tumor killing macrophages (M1) or tumor promoting macrophages (M2). So, the best way to target tumor-infiltrating macrophage is not depleting them but rather converting M2 into M1 phenotype [113, 114]. A low nontoxic dose of dopamine can modulate TAM polarization from M2 to M1 in rat C6 glioma via DRD2 signaling have been documented [115].

\section{Challenges and Perspectives}

Though several DRs agonists or antagonists have been applied to anti-tumor in clinical, there is still some problem exist. First, the efficacy of DRs agonists or antagonists depends largely on the expression level of DRs. The expression level of DRs would be a significant difference in different kinds of tumor and even in different stages of tumor development. High level expression of DRs usually gets a satisfactory therapeutic, contrast to low level expression of DRs. Just as Roney MSI and Park SK said, targeting dopamine receptor by blocking or activating, is an essential strategy to overcome cancer. However, the therapeutic effect depends on the type of tumor and the activity of dopamine receptors [116]. Second, though some dopamine receptor agonists or antagonists have been shown to inhibit tumor growth, there is no clear evidence that the anti-tumor effect is through dopamine receptors. For example, the anti-tumor effect of olanzapine, a DRD2 antagonist, has been demonstrated in glioblastoma cell lines, lung and pancreatic cancer stem cell lines in vitro [117-119], while there is no evidence that dopamine receptors are involved in olanzapine anticancer process. Third, in some cancer dopamine receptors involved the anti-cancer of DRs agonists or antagonists, while in other cancers the DRs agonists or antagonists may exert its role of antitumor through a non-DR related mechanisms. For example, pimpzide can inhibit the proliferation of pancreatic cancer cells via inhibition of DRD2 [40], while pimozide can inhibit the growth of prostate cancer via suppression of STAT3 activation [120], and inhibit the growth glioblastoma via serotonin receptor 5-HT7 [121], whether dopamine receptor take part in the pimozide's role of anti-cancer in prostate cancer and glioblastoma still unknown. 
Last but not least, treatment of tumors with dopamine analogs can also produce resistance, due to the change expression pattern of DRs [122]. Therefore, it is extremely important to know the detail expression patterns of DRs change in cancerous condition. However, there is still no clear report on this aspect. And current researches are focused on the function of DRD1 and DRD2 in tumors, very few studies on other DRs. Future research should focus on exploring the expression patterns of DRs in different stages of tumor development, so as to select appropriate dopamine-receptor agonist or antagonist to inhibit tumor progression. This is a key factor. And for some non-selective dopamine-receptor agonists or antagonists, we cannot rule out that their anti-cancer effects may not be through dopamine receptors, or that dopamine receptors are not a key factor in their anti-cancer effects. So the development of a more selective dopamine-receptor agonist or antagonist is another key factor in the future treatment of dopamine-receptor related cancers through dopamine receptors.

\section{Search Strategy}

A comprehensive literature screening was conducted for publication up to August 30th, 2018 from the following databases: (1) Pubmed; (2) Web of Science; (3) Google Scholar. Search terms:" dopamine, DA", " dopamine receptors, DRs", "cancer, tumor, carcinoma, neoplasm", "autophagy", "ferroptosis", "immunity" were used in combination to retrieve the relevant literature.

\section{Acknowledgments}

This work was supported by the National Key Research and Development Program of China (2016Y FC1306900), National Natural Science Foundation of China (81573508), and Open Foundation of Innovative Platform in Colleges and University of Hunan Province of China ([2015]54).

\section{Competing Interests}

The authors have declared that no competing interest exists.

\section{References}

1. Beaulieu JM, Gainetdinov RR. The physiology, signaling, and pharmacology of dopamine receptors. Pharmacol Rev. 2011; 63: 182-217.

2. Peters MA, Walenkamp AM, Kema IP, Meijer C, de Vries EG, Oosting SF. Dopamine and serotonin regulate tumor behavior by affecting angiogenesis. Drug Resist Updat. 2014; 17: 96-104.

3. Eisenhofer G, Aneman A, Friberg P, Hooper D, Fandriks L, Lonroth H, et al. Substantial production of dopamine in the human gastrointestinal tract. The Journal of clinical endocrinology and metabolism. 1997; 82: 3864-71.

4. Vallone D, Picetti R, Borrelli E. Structure and function of dopamine receptors. Neuroscience and biobehavioral reviews. 2000; 24: 125-32.

5. Basu B, Sarkar C, Chakroborty D, Ganguly S, Shome S, Dasgupta PS, et al. D1 and D2 dopamine receptor-mediated inhibition of activated normal $\mathrm{T}$ cell proliferation is lost in jurkat $\mathrm{T}$ leukemic cells. The Journal of biological chemistry. 2010; 285: 27026-32.
6. Sealfon SC, Olanow CW. Dopamine receptors: from structure to behavior. Trends in neurosciences. 2000; 23: S34-40.

7. Levite M. Dopamine and T cells: dopamine receptors and potent effects on T cells, dopamine production in T cells, and abnormalities in the dopaminergic system in T cells in autoimmune, neurological and psychiatric diseases. Acta physiologica (Oxford, England). 2016; 216: 42-89.

8. Gingrich JA, Caron MG. Recent advances in the molecular biology of dopamine receptors. Annual review of neuroscience. 1993; 16: 299-321.

9. Giros B, Martres MP, Pilon C, Sokoloff P, Schwartz JC. Shorter variants of the D3 dopamine receptor produced through various patterns of alternative splicing. Biochemical and biophysical research communications. 1991; 176: 1584-92.

10. Missale C, Nash SR, Robinson SW, Jaber M, Caron MG. Dopamine receptors: from structure to function. Physiological reviews. 1998; 78: 189-225.

11. Van Tol HH, Wu CM, Guan HC, Ohara K, Bunzow JR, Civelli O, et al. Multiple dopamine D4 receptor variants in the human population. Nature. 1992; 358: 149-52.

12. Howes OD, Kambeitz J, Kim E, Stahl D, Slifstein M, Abi-Dargham A, et al. The nature of dopamine dysfunction in schizophrenia and what this means for treatment. Archives of general psychiatry. 2012; 69: 776-86.

13. Ji J, Sundquist K, Ning Y, Kendler KS, Sundquist J, Chen X. Incidence of cancer in patients with schizophrenia and their first-degree relatives: a population-based study in Sweden. Schizophrenia bulletin. 2013; 39: 527-36.

14. Chou FH, Tsai KY, Su CY, Lee CC. The incidence and relative risk factors for developing cancer among patients with schizophrenia: a nine-year follow-up study. Schizophrenia research. 2011; 129: 97-103.

15. Li H, Li J, Yu X, Zheng H, Sun X, Lu Y, et al. The incidence rate of cancer in patients with schizophrenia: A meta-analysis of cohort studies. Schizophrenia research. 2017.

16. Wu Chou AI, Wang YC, Lin CL, Kao CH. Female schizophrenia patients and risk of breast cancer: A population-based cohort study. Schizophrenia research. 2017; 188: 165-71.

17. Agay N, Flaks-Manov N, Nitzan U, Hoshen MB, Levkovitz Y, Munitz H. Cancer prevalence in Israeli men and women with schizophrenia. Psychiatry research. 2017; 258: 262-7.

18. Arrillaga-Romany I, Chi AS, Allen JE, Oster W, Wen PY, Batchelor TT. A phase 2 study of the first imipridone ONC201, a selective DRD2 antagonist for oncology, administered every three weeks in recurrent glioblastoma. Oncotarget. 2017; 8: 79298-304.

19. Lin GM, Chen YJ, Kuo DJ, Jaiteh LE, Wu YC, Lo TS, et al. Cancer incidence in patients with schizophrenia or bipolar disorder: a nationwide population-based study in Taiwan, 1997-2009. Schizophrenia bulletin. 2013; 39: 407-16.

20. Dalton SO, Mellemkjaer L, Thomassen L, Mortensen PB, Johansen C. Risk for cancer in a cohort of patients hospitalized for schizophrenia in Denmark, 1969-1993. Schizophrenia research. 2005; 75: 315-24.

21. Rugbjerg K, Friis S, Lassen CF, Ritz B, Olsen JH. Malignant melanoma, breast cancer and other cancers in patients with Parkinson's disease. International journal of cancer. 2012; 131: 1904-11.

22. Fois AF, Wotton CJ, Yeates D, Turner MR, Goldacre MJ. Cancer in patients with motor neuron disease, multiple sclerosis and Parkinson's disease: record linkage studies. Journal of neurology, neurosurgery, and psychiatry. 2010; 81: 215-21.

23. Driver JA, Logroscino G, Buring JE, Gaziano JM, Kurth T. A prospective cohort study of cancer incidence following the diagnosis of Parkinson's disease. Cancer epidemiology, biomarkers \& prevention : a publication of the American Association for Cancer Research, cosponsored by the American Society of Preventive Oncology. 2007; 16: 1260-5

24. Murphy G, Cross AJ, Sansbury LS, Bergen A, Laiyemo AO, Albert PS, et al. Dopamine D2 receptor polymorphisms and adenoma recurrence in the Polyp Prevention Trial. International journal of cancer. 2009; 124: 2148-51.

25. Campa D, Zienolddiny S, Lind H, Ryberg D, Skaug V, Canzian F, et al Polymorphisms of dopamine receptor/transporter genes and risk of non-small cell lung cancer. Lung cancer (Amsterdam, Netherlands). 2007; 56: $17-23$

26. Mu J, Huang W, Tan Z, Li M, Zhang L, Ding Q, et al. Dopamine receptor D2 is correlated with gastric cancer prognosis. Oncology letters. 2017; 13: 1223-7.

27. Grossrubatscher E, Veronese S, Ciaramella PD, Pugliese R, Boniardi M, De Carlis L, et al. High expression of dopamine receptor subtype 2 in a large series of neuroendocrine tumors. Cancer biology \& therapy. 2008; 7: 1970-8.

28. Li J, Zhu S, Kozono D, Ng K, Futalan D, Shen Y, et al. Genome-wide shRNA screen revealed integrated mitogenic signaling between dopamine receptor D2 (DRD2) and epidermal growth factor receptor (EGFR) in glioblastoma. Oncotarget. 2014; 5: 882-93.

29. Akbari ME, Kashani FL, Ahangari G, Pornour M, Hejazi H, Nooshinfar E, et al. The effects of spiritual intervention and changes in dopamine receptor gene expression in breast cancer patients. Breast cancer (Tokyo, Japan). 2016; 23 : 893-900.

30. Unland R, Kerl K, Schlosser S, Farwick N, Plagemann T, Lechtape B, et al. Epigenetic repression of the dopamine receptor D4 in pediatric tumors of the central nervous system. Journal of neuro-oncology. 2014; 116: 237-49.

31. Dolma S, Selvadurai HJ, Lan X, Lee L, Kushida M, Voisin V, et al. Inhibition of Dopamine Receptor D4 Impedes Autophagic Flux, Proliferation, and Survival of Glioblastoma Stem Cells. Cancer cell. 2016; 29: 859-73. 
32. He $\mathrm{Q}$, Yuan LB. Dopamine inhibits proliferation, induces differentiation and apoptosis of K562 leukaemia cells. Chinese medical journal. 2007; 120: 970-4.

33. Terasaka H, Tamura A, Takayama F, Kashimata M, Ohtomo K, Machino M, et al. Induction of apoptosis by dopamine in human oral tumor cell lines. Anticancer research. 2000; 20: 243-50.

34. An JJ, Cho SR, Jeong DW, Park KW, Ahn YS, Baik JH. Anti-proliferative effects and cell death mediated by two isoforms of dopamine D2 receptors in pituitary tumor cells. Molecular and cellular endocrinology. 2003; 206: 49-62.

35. Chen J, Wersinger C, Sidhu A. Chronic stimulation of D1 dopamine receptors in human SK-N-MC neuroblastoma cells induces nitric-oxide synthase activation and cytotoxicity. The Journal of biological chemistry. 2003; 278: 28089-100.

36. Wang S, Mou Z, Ma Y, Li J, Li J, Ji X, et al. Dopamine enhances the response of sunitinib in the treatment of drug-resistant breast cancer: Involvement of eradicating cancer stem-like cells. Biochemical pharmacology. 2015; 95: 98-109.

37. Gao J, Gao F. Dopamine D1 receptors induce apoptosis of osteosarcoma cells via changes of MAPK pathway. Clinical and experimental pharmacology \& physiology. 2017; 44: 1166-8.

38. Akiyama S, Shiraishi N, Kuratomi Y, Nakagawa M, Kuwano M. Circumvention of multiple-drug resistance in human cancer cells by thioridazine, trifluoperazine, and chlorpromazine. Journal of the National Cancer Institute. 1986; 76: 839-44.

39. Mao M, Yu T, Hu J, Hu L. Dopamine D2 receptor blocker thioridazine induces cell death in human uterine cervical carcinoma cell line SiHa. The journal of obstetrics and gynaecology research. 2015; 41: 1240-5.

40. Jandaghi P, Najafabadi HS, Bauer AS, Papadakis AI, Fassan M, Hall A, et al. Expression of DRD2 Is Increased in Human Pancreatic Ductal Adenocarcinoma and Inhibitors Slow Tumor Growth in Mice. Gastroenterology. 2016; 151: 1218-31.

41. Giunta S, Castorina A, Adorno A, Mazzone V, Carnazza ML, D'Agata V. PACAP and VIP affect NF1 expression in rat malignant peripheral nerve sheath tumor (MPNST) cells. Neuropeptides. 2010; 44: 45-51.

42. Donarum EA, Halperin RF, Stephan DA, Narayanan V. Cognitive dysfunction in NF1 knock-out mice may result from altered vesicular trafficking of APP/DRD3 complex. BMC neuroscience. 2006; 7: 22.

43. Castorina A, Giunta S, D'Agata V. Protective effect of the dopamine $D(3)$ receptor agonist (7-OH-PIPAT) against apoptosis in malignant peripheral nerve sheath tumor (MPNST) cells. International journal of oncology. 2010; 37: 927-34.

44. Leng ZG, Lin SJ, Wu ZR, Guo YH, Cai L, Shang HB, et al. Activation of DRD5 (dopamine receptor D5) inhibits tumor growth by autophagic cell death. Autophagy. 2017; 13: 1404-19.

45. Galluzzi L, Baehrecke EH, Ballabio A, Boya P, Bravo-San Pedro JM, Cecconi F, et al. Molecular definitions of autophagy and related processes. The EMBO journal. 2017; 36: 1811-36.

46. Menzies FM, Fleming A, Caricasole A, Bento CF, Andrews SP, Ashkenazi A, et al. Autophagy and Neurodegeneration: Pathogenic Mechanisms and Therapeutic Opportunities. Neuron. 2017; 93: 1015-34.

47. Shin JH, Park SJ, Kim ES, Jo YK, Hong J, Cho DH. Sertindole, a potent antagonist at dopamine $\mathrm{D}(2)$ receptors, induces autophagy by increasing reactive oxygen species in SH-SY5Y neuroblastoma cells. Biological \& pharmaceutical bulletin. 2012; 35: 1069-75.

48. Chen J, Zhang L, Zhou H, Wang W, Luo Y, Yang H, et al. Inhibition of autophagy promotes cisplatin-induced apoptotic cell death through Atg5 and Beclin 1 in A549 human lung cancer cells. Molecular medicine reports. 2018; 17: 6859-65.

49. Wang Z, Liu Z, Wu S. Long non-coding RNA CTA sensitizes osteosarcoma cells to doxorubicin through inhibition of autophagy. Oncotarget. 2017; 8: 31465-77.

50. Wu S, Wang X, Chen J, Chen Y. Autophagy of cancer stem cells is involved with chemoresistance of colon cancer cells. Biochemical and biophysical research communications. 2013; 434: 898-903.

51. Gomez-Santos C, Ferrer I, Santidrian AF, Barrachina M, Gil J, Ambrosio S. Dopamine induces autophagic cell death and alpha-synuclein increase in human neuroblastoma SH-SY5Y cells. Journal of neuroscience research. 2003; 73: 341-50.

52. Wang JD, Cao YL, Li Q, Yang YP, Jin M, Chen D, et al. A pivotal role of FOS-mediated BECN1/Beclin 1 upregulation in dopamine D2 and D3 receptor agonist-induced autophagy activation. Autophagy. 2015; 11: 2057-73.

53. Yong M, Yu T, Tian S, Liu S, Xu J, Hu J, et al. DR2 blocker thioridazine: A promising drug for ovarian cancer therapy. Oncology letters. 2017; 14: 8171-7.

54. Cheong $\mathrm{H}$, Lindsten $\mathrm{T}, \mathrm{Wu} \mathrm{J}$, Lu C, Thompson CB. Ammonia-induced autophagy is independent of ULK1/ULK2 kinases. Proceedings of the National Academy of Sciences of the United States of America. 2011; 108: 11121-6.

55. Li Z, Ji X, Wang W, Liu J, Liang X, Wu H, et al. Ammonia Induces Autophagy through Dopamine Receptor D3 and MTOR. PloS one. 2016; 11: e0153526.

56. Galluzzi L, Vitale I, Aaronson SA, Abrams JM, Adam D, Agostinis P, et al. Molecular mechanisms of cell death: recommendations of the Nomenclature Committee on Cell Death 2018. Cell death and differentiation. 2018; 25: 486-541.

57. Shen Z, Song J, Yung BC, Zhou Z, Wu A, Chen X. Emerging Strategies of Cancer Therapy Based on Ferroptosis. Advanced materials (Deerfield Beach, Fla). 2018; 30: e1704007.
58. Yu Y, Xie Y, Cao L, Yang L, Yang M, Lotze MT, et al. The ferroptosis inducer erastin enhances sensitivity of acute myeloid leukemia cells to chemotherapeutic agents. Molecular \& cellular oncology. 2015; 2: e1054549.

59. Wang D, Peng Y, Xie Y, Zhou B, Sun X, Kang R, et al. Antiferroptotic activity of non-oxidative dopamine. Biochemical and biophysical research communications. 2016; 480: 602-7.

60. Teunis MA, Kavelaars A, Voest E, Bakker JM, Ellenbroek BA, Cools AR, et al. Reduced tumor growth, experimental metastasis formation, and angiogenesis in rats with a hyperreactive dopaminergic system. FASEB journal : official publication of the Federation of American Societies for Experimental Biology. 2002; 16: 1465-7.

61. Moreno-Smith M, Lu C, Shahzad MM, Pena GN, Allen JK, Stone RL, et al. Dopamine blocks stress-mediated ovarian carcinoma growth. Clinical cancer research : an official journal of the American Association for Cancer Research. 2011; 17: 3649-59.

62. Chakroborty D, Sarkar C, Mitra RB, Banerjee S, Dasgupta PS, Basu S. Depleted dopamine in gastric cancer tissues: dopamine treatment retards growth of gastric cancer by inhibiting angiogenesis. Clinical cancer research : an official journal of the American Association for Cancer Research. 2004; 10: 4349-56.

63. Sarkar C, Chakroborty D, Chowdhury UR, Dasgupta PS, Basu S. Dopamine increases the efficacy of anticancer drugs in breast and colon cancer preclinical models. Clinical cancer research : an official journal of the American Association for Cancer Research. 2008; 14: 2502-10.

64. Coufal M, Invernizzi P, Gaudio E, Bernuzzi F, Frampton GA, Onori P, et al. Increased local dopamine secretion has growth-promoting effects in cholangiocarcinoma. International journal of cancer. 2010; 126: 2112-22.

65. Chakroborty D, Sarkar C, Basu B, Dasgupta PS, Basu S. Catecholamines regulate tumor angiogenesis. Cancer research. 2009; 69: 3727-30.

66. Basu S, Sarkar C, Chakroborty D, Nagy J, Mitra RB, Dasgupta PS, et al. Ablation of peripheral dopaminergic nerves stimulates malignant tumor growth by inducing vascular permeability factor/vascular endothelial growth factor-mediated angiogenesis. Cancer research. 2004; 64: 5551-5.

67. Hoeppner LH, Wang Y, Sharma A, Javeed N, Van Keulen VP, Wang E, et al. Dopamine D2 receptor agonists inhibit lung cancer progression by reducing angiogenesis and tumor infiltrating myeloid derived suppressor cells. Molecular oncology. 2015; 9: 270-81

68. Basu S, Nagy JA, Pal S, Vasile E, Eckelhoefer IA, Bliss VS, et al. The neurotransmitter dopamine inhibits angiogenesis induced by vascular permeability factor/vascular endothelial growth factor. Nature medicine. 2001; 7: 569-74.

69. Ganguly S, Basu B, Shome S, Jadhav T, Roy S, Majumdar J, et al. Dopamine, by acting through its D2 receptor, inhibits insulin-like growth factor-I (IGF-I)-induced gastric cancer cell proliferation via up-regulation of Kruppel-like factor 4 through down-regulation of IGF-IR and AKT phosphorylation. The American journal of pathology. 2010; 177: 2701-7.

70. Cherubini E, Di Napoli A, Noto A, Osman GA, Esposito MC, Mariotta S, et al. Genetic and Functional Analysis of Polymorphisms in the Human Dopamine Receptor and Transporter Genes in Small Cell Lung Cancer. Journal of cellular physiology. 2016; 231: 345-56

71. Roy S, Lu K, Nayak MK, Bhuniya A, Ghosh T, Kundu S, et al. Activation of D2 Dopamine Receptors in CD133+ve Cancer Stem Cells in Non-small Cell Lung Carcinoma Inhibits Proliferation, Clonogenic Ability, and Invasiveness of These Cells. The Journal of biological chemistry. 2017; 292: 435-45.

72. Liu XF, Long HJ, Miao XY, Liu GL, Yao HL. Fisetin inhibits liver cancer growth in a mouse model: Relation to dopamine receptor. Oncology reports. 2017; 38: 53-62

73. Pornour M, Ahangari G, Hejazi SH, Deezagi A. New perspective therapy of breast cancer based on selective dopamine receptor D2 agonist and antagonist effects on MCF-7 cell line. Recent patents on anti-cancer drug discovery. 2015; 10: $214-23$.

74. Chang HW, Huang CY, Yang SY, Wu VC, Chu TS, Chen YM, et al. Role of D2 dopamine receptor in adrenal cortical cell proliferation and aldosterone-producing adenoma tumorigenesis. Journal of molecular endocrinology. 2014; 52: 87-96.

75. Zhang QB, Zhang BH, Zhang KZ, Meng XT, Jia QA, Zhang OB, et al. Moderate swimming suppressed the growth and metastasis of the transplanted liver cancer in mice model: with reference to nervous system. Oncogene. 2016; 35: 4122-31.

76. Gao H, Wang F, Lan X, Li C, Feng J, Bai J, et al. Lower PRDM2 expression is associated with dopamine-agonist resistance and tumor recurrence in prolactinomas. BMC cancer. 2015; 15: 272.

77. Yin T, He S, Shen G, Ye T, Guo F, Wang Y. Dopamine receptor antagonist thioridazine inhibits tumor growth in a murine breast cancer model. Molecular medicine reports. 2015; 12: 4103-8

78. Sachlos E, Risueno RM, Laronde S, Shapovalova Z, Lee JH, Russell J, et al. Identification of drugs including a dopamine receptor antagonist that selectively target cancer stem cells. Cell. 2012; 149: 1284-97.

79. Byun HJ, Lee JH, Kim BR, Kang S, Dong SM, Park MS, et al. Anti-angiogenic effects of thioridazine involving the FAK-mTOR pathway. Microvascular research. 2012; 84: 227-34.

80. Park MS, Dong SM, Kim BR, Seo SH, Kang S, Lee EJ, et al. Thioridazine inhibits angiogenesis and tumor growth by targeting the VEGFR-2/PI3K/mTOR pathway in ovarian cancer xenografts. Oncotarget. 2014; 5: 4929-34. 
81. Pinheiro T, Otrocka M, Seashore-Ludlow B, Rraklli V, Holmberg J, Forsberg-Nilsson K, et al. Reprint of: A chemical screen identifies trifluoperazine as an inhibitor of glioblastoma growth. Biochemical and biophysical research communications. 2018; 499: 136-42.

82. Yeh CT, Wu AT, Chang PM, Chen KY, Yang CN, Yang SC, et al. Trifluoperazine, an antipsychotic agent, inhibits cancer stem cell growth and overcomes drug resistance of lung cancer. American journal of respiratory and critical care medicine. 2012; 186: 1180-8

83. Shen J, Ma B, Zhang X, Sun X, Han J, Wang Y, et al. Thioridazine has potent antitumor effects on lung cancer stem-like cells. Oncology letters. 2017; 13: $1563-8$

84. Kline CLB, Ralff MD, Lulla AR, Wagner JM, Abbosh PH, Dicker DT, et al. Role of Dopamine Receptors in the Anticancer Activity of ONC201. Neoplasia (New York, NY). 2018; 20: 80-91.

85. Li J, Yao QY, Xue JS, Wang LJ, Yuan Y, Tian XY, et al. Dopamine D2 receptor antagonist sulpiride enhances dexamethasone responses in the treatment of drug-resistant and metastatic breast cancer. Acta pharmacologica Sinica. 2017; 38: 1282-96.

86. Asada M, Ebihara S, Numachi Y, Okazaki T, Yamanda S, Ikeda K, et al. Reduced tumor growth in a mouse model of schizophrenia, lacking the dopamine transporter. International journal of cancer. 2008; 123: 511-8

87. Gao J, Zhang C, Gao F, Li H. The effect and mechanism of dopamine D1 receptors on the proliferation of osteosarcoma cells. Molecular and cellular biochemistry. 2017; 430: 31-6.

88. Minami K, Liu S, Liu Y, Chen A, Wan Q, Na S, et al. Inhibitory Effects of Dopamine Receptor D1 Agonist on Mammary Tumor and Bone Metastasis. Scientific reports. 2017; 7: 45686.

89. Moreno-Smith M, Lee SJ, Lu C, Nagaraja AS, He G, Rupaimoole R, et al. Biologic effects of dopamine on tumor vasculature in ovarian carcinoma. Neoplasia (New York, NY). 2013; 15: 502-10.

90. Costa FB, Cortez AP, de Avila RI, de Carvalho FS, Andrade WM, da Cruz AF, et al. The novel piperazine-containing compound LQFM018: Necroptosis cell death mechanisms, dopamine D4 receptor binding and toxicological assessment. Biomedicine \& pharmacotherapy $=$ Biomedecine \& pharmacotherapie. 2018; 102: 481-93.

91. Huang H, Wu K, Ma J, Du Y, Cao C, Nie Y. Dopamine D2 receptor suppresses gastric cancer cell invasion and migration via inhibition of EGFR/AKT/MMP-13 pathway. International immunopharmacology. 2016; 39: $113-20$

92. Peverelli E, Giardino E, Treppiedi D, Meregalli M, Belicchi M, Vaira V, et al. Dopamine receptor type 2 (DRD2) and somatostatin receptor type 2 (SSTR2) agonists are effective in inhibiting proliferation of progenitor/stem-like cells isolated from nonfunctioning pituitary tumors. International journal of cancer. 2017; 140: 1870-80.

93. Peverelli E, Giardino E, Treppiedi D, Locatelli M, Vaira V, Ferrero S, et al. Dopamine receptor type 2 (DRD2) inhibits migration and invasion of human tumorous pituitary cells through ROCK-mediated cofilin inactivation. Cancer letters. 2016; 381: 279-86.

94. Lu M, Li J, Luo Z, Zhang S, Xue S, Wang K, et al. Roles of dopamine receptors and their antagonist thioridazine in hepatoma metastasis. OncoTargets and therapy. 2015; 8: 1543-52.

95. Pulkoski-Gross A, Li J, Zheng C, Li Y, Ouyang N, Rigas B, et al. Repurposing the antipsychotic trifluoperazine as an antimetastasis agent. Molecular pharmacology. 2015; 87: 501-12

96. Borcherding DC, Tong W, Hugo ER, Barnard DF, Fox S, LaSance $K$, et al. Expression and therapeutic targeting of dopamine receptor-1 (D1R) in breast cancer. Oncogene. 2016; 35: 3103-13.

97. Saha B, Mondal AC, Basu S, Dasgupta PS. Circulating dopamine level, in lung carcinoma patients, inhibits proliferation and cytotoxicity of CD4+ and CD8+ $\mathrm{T}$ cells by $\mathrm{D} 1$ dopamine receptors: an in vitro analysis. International immunopharmacology. 2001; 1: 1363-74.

98. Pinoli M, Marino F, Cosentino M. Dopaminergic Regulation of Innate Immunity: a Review. Journal of neuroimmune pharmacology : the official journal of the Society on NeuroImmune Pharmacology. 2017; 12: 602-23.

99. Mikulak J, Bozzo L, Roberto A, Pontarini E, Tentorio P, Hudspeth K, et al. Dopamine inhibits the effector functions of activated NK cells via the upregulation of the D5 receptor. Journal of immunology (Baltimore, Md : 1950). 2014; 193: 2792-800.

100. Besser MJ, Ganor Y, Levite M. Dopamine by itself activates either D2, D3 or D1/D5 dopaminergic receptors in normal human T-cells and triggers the selective secretion of either IL-10, TNFalpha or both. Journal of neuroimmunology. 2005; 169: 161-71.

101. Zhang X, Liu Q, Liao Q, Zhao Y. Potential Roles of Peripheral Dopamine in Tumor Immunity. Journal of Cancer. 2017; 8: 2966-73

102. Pacheco R, Prado CE, Barrientos MJ, Bernales S. Role of dopamine in the physiology of T-cells and dendritic cells. Journal of neuroimmunology. 2009; 216: 8-19.

103. Watanabe Y, Nakayama T, Nagakubo D, Hieshima K, Jin Z, Katou F, et al. Dopamine selectively induces migration and homing of naive $\mathrm{CD} 8+\mathrm{T}$ cells via dopamine receptor D3. Journal of immunology (Baltimore, Md : 1950). 2006; 176: 848-56.

104. Kustrimovic N, Rasini E, Legnaro M, Marino F, Cosentino M. Expression of dopaminergic receptors on human CD4+ $\mathrm{T}$ lymphocytes: flow cytometric analysis of naive and memory subsets and relevance for the neuroimmunology of neurodegenerative disease. Journal of neuroimmune pharmacology : the official journal of the Society on NeuroImmune Pharmacology. 2014; 9: 302-12.

105. Figueroa C, Galvez-Cancino F, Oyarce C, Contreras F, Prado C, Valeria C, et al. Inhibition of dopamine receptor D3 signaling in dendritic cells increases antigen cross-presentation to $\mathrm{CD} 8(+)$ T-cells favoring anti-tumor immunity. Journal of neuroimmunology. 2017; 303: 99-107.

106. Nakano K, Higashi T, Takagi R, Hashimoto K, Tanaka Y, Matsushita S. Dopamine released by dendritic cells polarizes Th2 differentiation. International immunology. 2009; 21: 645-54.

107. Parker KH, Beury DW, Ostrand-Rosenberg S. Myeloid-Derived Suppressor Cells: Critical Cells Driving Immune Suppression in the Tumor Microenvironment. Advances in cancer research. 2015; 128: 95-139.

108. Wu J, Zhang R, Tang N, Gong Z, Zhou J, Chen Y, et al. Dopamine inhibits the function of Gr-1+CD115+ myeloid-derived suppressor cells through D1-like receptors and enhances anti-tumor immunity. Journal of leukocyte biology. 2015; 97: 191-200.

109. Movahedi K, Guilliams M, Van den Bossche J, Van den Bergh R, Gysemans C, Beschin A, et al. Identification of discrete tumor-induced myeloid-derived suppressor cell subpopulations with distinct T cell-suppressive activity. Blood. 2008; 111: 4233-44.

110. Dyck L, Lynch L. New Job for NK Cells: Architects of the Tumor Microenvironment. Immunity. 2018; 48: 9-11.

111. Ogura K, Sato-Matsushita M, Yamamoto S, Hori T, Sasahara M, Iwakura Y, et al. NK Cells Control Tumor-Promoting Function of Neutrophils in Mice. Cancer immunology research. 2018.

112. Chen D, Xie J, Fiskesund R, Dong W, Liang X, Lv J, et al. Chloroquine modulates antitumor immune response by resetting tumor-associated macrophages toward M1 phenotype. Nature communications. 2018; 9: 873

113. Murray PJ, Allen JE, Biswas SK, Fisher EA, Gilroy DW, Goerdt S, et al. Macrophage activation and polarization: nomenclature and experimental guidelines. Immunity. 2014; 41: 14-20.

114. Hoves S, Ooi CH, Wolter C, Sade H, Bissinger S, Schmittnaegel M, et al. Rapid activation of tumor-associated macrophages boosts preexisting tumor immunity. The Journal of experimental medicine. 2018; 215: 859-76.

115. Qin T, Wang C, Chen X, Duan C, Zhang X, Zhang J, et al. Dopamine induces growth inhibition and vascular normalization through reprogramming M2-polarized macrophages in rat C6 glioma. Toxicology and applied pharmacology. 2015; 286: 112-23.

116. Roney MSI, Park SK. Antipsychotic dopamine receptor antagonists, cancer, and cancer stem cells. Archives of pharmacal research. 2018; 41: 384-408.

117. Wang YX, Xu SQ, Chen XH, Liu RS, Liang ZQ. Autophagy involvement in olanzapine-mediated cytotoxic effects in human glioma cells. Asian Pacific journal of cancer prevention : APJCP. 2014; 15: 8107-13.

118. Karpel-Massler G, Kast RE, Westhoff MA, Dwucet A, Welscher N, Nonnenmacher $\mathrm{L}$, et al. Olanzapine inhibits proliferation, migration and anchorage-independent growth in human glioblastoma cell lines and enhances temozolomide's antiproliferative effect. Journal of neuro-oncology. 2015; 122 : 21-33.

119. Sanomachi T, Suzuki S, Kuramoto K, Takeda H, Sakaki H, Togashi K, et al. Olanzapine, an Atypical Antipsychotic, Inhibits Survivin Expression and Sensitizes Cancer Cells to Chemotherapeutic Agents. Anticancer research. 2017; 37: 6177-88.

120. Zhou W, Chen MK, Yu HT, Zhong ZH, Cai N, Chen GZ, et al. The antipsychotic drug pimozide inhibits cell growth in prostate cancer through suppression of STAT3 activation. International journal of oncology. 2016; 48: $322-8$

121. Kast RE. Glioblastoma chemotherapy adjunct via potent serotonin receptor-7 inhibition using currently marketed high-affinity antipsychotic medicines. British journal of pharmacology. 2010; 161: 481-7.

122. Shimazu S, Shimatsu A, Yamada S, Inoshita N, Nagamura Y, Usui T, et al. Resistance to dopamine agonists in prolactinoma is correlated with reduction of dopamine D2 receptor long isoform mRNA levels. European journal of endocrinology. 2012; 166: 383-90.

123. Gemignani F, Landi S, Moreno V, Gioia-Patricola L, Chabrier A, Guino E, et al. Polymorphisms of the dopamine receptor gene DRD2 and colorectal cancer risk. Cancer epidemiology, biomarkers \& prevention : a publication of the American Association for Cancer Research, cosponsored by the American Society of Preventive Oncology. 2005; 14: 1633-8.

124. de Bruin C, Pereira AM, Feelders RA, Romijn JA, Roelfsema F, Sprij-Mooij $\mathrm{DM}$, et al. Coexpression of dopamine and somatostatin receptor subtypes in corticotroph adenomas. The Journal of clinical endocrinology and metabolism. 2009; 94: 1118-24

125. Kanakis G, Grimelius L, Spathis A, Tringidou R, Rassidakis GZ, Oberg K, et al. Expression of Somatostatin Receptors 1-5 and Dopamine Receptor 2 in Lung Carcinoids: Implications for a Therapeutic Role. Neuroendocrinology. 2015; 101: $211-22$

126. Diakatou E, Kaltsas G, Tzivras M, Kanakis G, Papaliodi E, Kontogeorgos G. Somatostatin and dopamine receptor profile of gastroenteropancreatic neuroendocrine tumors: an immunohistochemical study. Endocr Pathol. 2011; 22: $24-30$.

127. Srirajaskanthan R, Watkins J, Marelli L, Khan K, Caplin ME. Expression of somatostatin and dopamine 2 receptors in neuroendocrine tumours and the potential role for new biotherapies. Neuroendocrinology. 2009; 89: 308-14.

128. Saveanu A, Muresan M, De Micco C, Taieb D, Germanetti AL, Sebag F, et al. Expression of somatostatin receptors, dopamine $\mathrm{D}(2)$ receptors, noradrenaline 
transporters, and vesicular monoamine transporters in 52 pheochromocytomas and paragangliomas. Endocr Relat Cancer. 2011; 18: 287-300.

129. Saveanu A, Sebag F, Guillet B, Archange C, Essamet W, Barlier A, et al. Targeting dopamine receptors subtype 2 (D2DR) in pheochromocytomas: head-to-head comparison between in vitro and in vivo findings. The Journal of clinical endocrinology and metabolism. 2013; 98: E1951-5.

130. Gabalec F, Drastikova M, Cesak T, Netuka D, Masopust V, Machac J, et al. Dopamine 2 and somatostatin 1-5 receptors coexpression in clinically non-functioning pituitary adenomas. Physiological research. 2015; 64: 369-77. 